\title{
Modeling the influence of temperature and water potential on seed germination of Allium tenuissimum $\mathrm{L}$.
}

\author{
Hong Xiao ${ }^{1}$, Helong Yang ${ }^{1}$, Thomas Monaco ${ }^{2}$, Qian Song ${ }^{1}$, Yuping Rong ${ }^{\text {Corresp. } 1}$ \\ ${ }^{1}$ Beijing Key Laboratory of Grassland Science, College of Grassland Science and Technology, China Agricultural University, Beijing, China \\ 2 USDA-ARS Forage and Range Research Laboratory, Utah State University, Logan, Utah, United States \\ Corresponding Author: Yuping Rong \\ Email address: rongyuping@cau.edu.cn
}

Allium tenuissimum $\mathrm{L}$. is a widely distributed perennial herbaceous species in temperate and desert steppes. Relative to other wild Allium species, it produces unique sweet flavors, more biomass in arid and cold environments, and has generated greater interest for crop production. Successful crop establishment, however, will depend on rapid and uniform seed germination. Our study aimed to characterize seed germination of $A$. tenuissimum under various temperature regimes $\left(11,15,20,24\right.$ and $\left.28^{\circ} \mathrm{C}\right)$ and water potential levels $(0,-0.2,-0.4$ and $-0.6 \mathrm{MPa})$, and model germination by hydrotime (HT) and hydrothermal time (HTT) analysis. Final germination percentage (FGP) increased within the range of 11 to $20^{\circ} \mathrm{C}$, yet it declined within the range of 24 to $28^{\circ} \mathrm{C}$ and generally decreased as water potential became more negative within each temperature setting. Maximum FGP was observed at $20{ }^{\circ} \mathrm{C}$ at all water potential settings and ranged from $55.0 \pm 5.3$ to $94.8 \pm 1.4$ $\%$. According to HT and HTT models, the base $\left(T_{\mathrm{b}}\right)$ and optimum temperatures $\left(T_{0}\right)$ for seed germination were 7.0 and $20.5^{\circ} \mathrm{C}$, respectively. In addition, base water potential for the fraction of germination within the seed lot $\left(\psi_{\mathrm{b}}(\mathrm{g})\right)$ shifted to $0 \mathrm{MPa}$ as temperature increased from $T_{\mathrm{b}}$ to ceiling temperature $\left(T_{\mathrm{c}}\right)$. For obtaining $50 \%$ seed germination, $\Psi_{\mathrm{b}}(50)$ and $T_{\mathrm{c}}(50)$ were estimated to be $-0.67 \mathrm{MPa}$ and $27.2{ }^{\circ} \mathrm{C}$, respectively. These values for $T_{\mathrm{b}}$ and $\Psi_{\mathrm{b}}(50)$ suggest seed germination of $A$. tenuissimum is both cold and drought tolerant and suitable for production in semi-arid regions. Our characterization of the ideal sowing conditions for $A$. tenuissimum, i.e., $20.5^{\circ} \mathrm{C}$ and soil water potential less negative than $-0.67 \mathrm{MPa}$ offers information to forecast suitable settings to enhance crop production. 
1 Modeling the influence of temperature and water

2

3

4

5

6

$7 \quad{ }^{1}$ Beijing Key Laboratory of Grassland Science, College of Grassland Science and Technology,

8 China Agricultural University, Beijing 100193, China

$9 \quad{ }^{2}$ USDA-ARS Forage and Range Research Laboratory, Utah State University, Logan, UT 84322-

10 6300, USA.

11

12

13

14

15

16

\section{potential on seed germination of Allium tenuissimum}

L.

Hong Xiao ${ }^{1}$, Helong Yang ${ }^{1}$, Thomas Monaco ${ }^{2}$, Qian Song ${ }^{1}$, Yuping Rong ${ }^{1}$$$
6300, \text { USA. }
$$

Corresponding author:

Yuping Rong ${ }^{1}$

Beijing Key Laboratory of Grassland Science, College of Grassland Science and Technology, China Agricultural University, Beijing 100193, China.

Email address: rongyuping@cau.edu.cn 


\section{Abstract}

Allium tenuissimum L. is a widely distributed perennial herbaceous species in temperate and desert steppes. Relative to other wild Allium species, it produces unique sweet flavors, more biomass in arid and cold environments, and has generated greater interest for crop production. Successful crop establishment, however, will depend on rapid and uniform seed germination. Our study aimed to characterize seed germination of A. tenuissimum under various temperature regimes $\left(11,15,20,24\right.$ and $\left.28^{\circ} \mathrm{C}\right)$ and water potential levels $(0,-0.2,-0.4$ and $-0.6 \mathrm{MPa})$, and model germination by hydrotime (HT) and hydrothermal time (HTT) analysis. Final germination percentage (FGP) increased within the range of 11 to $20^{\circ} \mathrm{C}$, yet it declined within the range of 24 to $28^{\circ} \mathrm{C}$ and generally decreased as water potential became more negative within each temperature setting. Maximum FGP was observed at $20^{\circ} \mathrm{C}$ at all water potential settings and ranged from $55.0 \pm 5.3$ to $94.8 \pm 1.4 \%$. According to HT and HTT models, the base $\left(T_{\mathrm{b}}\right)$ and optimum temperatures $\left(T_{\mathrm{o}}\right)$ for seed germination were 7.0 and $20.5^{\circ} \mathrm{C}$, respectively. In addition, base water potential for the fraction of germination within the seed lot $\left(\Psi_{\mathrm{b}}(\mathrm{g})\right)$ shifted to $0 \mathrm{MPa}$ as temperature increased from $T_{\mathrm{b}}$ to ceiling temperature $\left(T_{\mathrm{c}}\right)$. For obtaining $50 \%$ seed germination, $\Psi_{\mathrm{b}}(50)$ and $T_{\mathrm{c}}(50)$ were estimated to be $-0.67 \mathrm{MPa}$ and $27.2^{\circ} \mathrm{C}$, respectively. These values for $T_{\mathrm{b}}$ and $\Psi_{\mathrm{b}}(50)$ suggest seed germination of $A$. tenuissimum is both cold and drought tolerant and suitable for production in semi-arid regions. Our characterization of the ideal sowing conditions for $A$. tenuissimum, i.e., $20.5^{\circ} \mathrm{C}$ and soil water potential less negative than $-0.67 \mathrm{MPa}$ offers information to forecast suitable settings to enhance crop production.

\section{Introduction}

Seed germination is an essential process in establishing stable plant populations and is regulated by many environmental factors (Atashi et al., 2015; Juan-Vicedo et al., 2016). Among these factors, temperature and moisture conditions strongly regulate germination dynamics (Bakhshandeh and Gholamhossieni, 2019), and characterizing the base, optimum, and ceiling temperatures is one way of describing how temperature influences seed germination dynamics (Bakhshandeh et al., 2013; Bewley et al., 2013). Furthermore, thermal time (TT) models can be applied to predict seed germination dynamics across a range of temperatures (Mccartan et al., 2015; Bidgolya et al., 2018; Trudgill et al., 2005) and have proven useful in estimating germination under the dynamic temperatures of field seedbeds (Rawlins et al., 2012; Izquierdo et al., 2013). However, TT models may inaccurately predict seed germination responses under supra-optimal temperature ranges (Bakhshandeh et al., 2015; Bradford, 2002).

Germination is also very sensitive to moisture conditions and water deficiency-induced osmotic stress is known to prevent seed germination or slow germination rates (Tobe et al., 2001). Accordingly, water status is typically reported as osmotic water potential, and hydrotime (HT) models are typically applied to simultaneously account for changes in both final germination percentage and germination rate across variable water potential levels (Soltani et al., 2017; Bakhshandeh and Gholamhossieni, 2018). Furthermore, the combination of HT and TT models have produced hydrothermal time (HTT) models (Alvarado and Bradford, 2002; 
Gummerson, 1986) capable of determining the hydrothermal accumulation for seed germination at various temperature and water potential conditions and predict the time course of seed germination even across sub-optimal (Gummerson, 1986) and supra-optimal temperature ranges (Alvarado and Bradford, 2002). Consequently, parameters of HTT models can be used to characterize the physiological status of seed populations in response to variable temperature and water potential and have been widely applied to predict germination dynamics in numerous crops such as safflower (Carthamus tinctorius) (Bidgolya et al., 2018; Torabi et al., 2016), sesame (Sesamum indicum) (Bakhshandeh et al., 2017), zucchini (Cucurbita pepo) (Atashi et al., 2015), and watermelon (Citrullus vulgaris cv. 'Crimson sweet') (Bakhshandeh et al., 2015) and other wild species (Abdellaoui et al., 2019; Fakhfakh et al., 2018; Horn et al., 2015).

Allium tenuissimum L. is a perennial herbaceous species distributed in temperate and desert steppes of north-central Asia (He, 2008; Li et al., 2011). Within these ecosystems, it plays a critical role in sand fixation and conservation of water and soil due to having a well-developed fibrous root system and high tolerance of environmental stresses (Zhao, 2010). It is also recognized as a high-quality forage for herbivores (Song et al., 2016) and has economic importance due to its distinctive and tasty flavor (Li and Zhang 2011; Zhang and Liu, 2012). Consequently, it is highly valued as a vegetable or food seasoning (Li and Zhang 2011; Liu et al., 2016) and has generated interest in exploring new harvesting methods (Zhang et al., 2014), potential ways to extract essential oil from its flowers (Zhang and Liu, 2012), and identifying the unique volatile flavor compounds in flowers of $A$. tenuissimum (Xu et al., 2017). Despite these favorable qualities, establishing crops of $A$. tenuissimum on large-scales is not feasible by propagation of bulb tillers, but may become economically viable through propagation by seeds (Li et al., 2013; Zhao et al., 2011). Therefore, exploring seed germination dynamics under variable environmental conditions is an important step toward industrialized production. In this study, we aimed to focus on the response of seed germination to various temperatures and water potential conditions in A. tenuissimum: (i) characterizing seed germination dynamics of $A$. tenuissimum using HT and HTT models, and (ii) defining cardinal temperatures and base water potentials for $A$. tenuissimum seeds based on model parameters.

\section{Materials \& methods}

\section{Seed germination}

Seeds of $A$. teniussimum were collected from a temperate desert steppe area in Dongsu County [4351'36" N, 113 40'02" E, 1060 m a.s.l. (meters above sea level)], Inner Mongolia during October 2015 (approved by Yuping Rong, China Agricultural University). After that, the seeds were naturally dried, surface cleaned and put into a sealed glass container, and then stored at 4 ${ }^{\circ} \mathrm{C}$ in a refrigerator until needed for experimentation (April 2016).

Germination assays were conducted in a growth chamber (SPX-250-GB, Hengyu, China) located at the Grassland Science Department, China Agricultural University, Beijing, China with an $8 \mathrm{~h}$ light/16 h dark day/night lighting pattern. The light intensity and relative humidity were set as $6000 \mathrm{~lx}$ and 50\%. Mature Seeds were sterilized for 5 min with $10 \% \mathrm{NaClO}$ and then washed with distilled water (Rong et al., 2015). For the germination tests, 100 seeds were placed 
in glass Petri dishes (90 mm inner diameter) containing two layers of filter paper (1001-090, Whatman, UK) saturated with distilled water ( $\Psi=0 \mathrm{MPa}$ ) or solutions of different water potential levels ( $\Psi=-0.2,-0.4$ and $-0.6 \mathrm{MPa}$ ). Petri dishes were then transferred to the chamber and germination was characterized at four constant temperature settings $(11,15,20,24$ and 28 ${ }^{\circ} \mathrm{C}$ ), each replicated four times for each water potential level. Different water potential levels were produced by mixing aqueous solutions of polyethylene glycol (PEG) 6000 with distilled water according to Michel and Kaufmann (1973). A vapour pressure osmometer (Model 5100C, Wescor, Inc., Logan, UT, USA) was used to measure $\Psi$ of solutions and create desired levels for all temperature settings. To maintain constant $\Psi$ and avoid fungal attack, seeds incubated on PEG 6000 solutions were transferred to fresh solutions every $2 \mathrm{~d}$. Germination was scored daily by observing radicle protrusion. Seed germination was defined depend on the length of radicle. Normally seeds were regarded as germinated when the length of radicle was more than $2 \mathrm{~mm}$ (Saleem et al., 2019). To avoid errors in recording germination, germinated seeds were removed after being counted. Furthermore, germination tests were terminated when no new germinated seeds were counted for three consecutive days.

\section{Germination analysis}

Germination rates $\left(\mathrm{GR}_{\mathrm{g}}\right)$ were calculated using the equation: $\mathrm{GR}_{\mathrm{g}}=1 / t_{\mathrm{g}}$, where $t_{\mathrm{g}}$ is the duration to radicle emergence. Estimations of germination rate for the $50^{\text {th }}$ percentile $\left(\mathrm{GR}_{50}\right)$ in each replicate were calculated by interpolation using curves fit to the time course data. To determine the optimal germination temperature, germination rates at 20 and $24^{\circ} \mathrm{C}$ were compared. If final germination percentage at $20^{\circ} \mathrm{C}$ was significantly greater than germination at $24^{\circ} \mathrm{C}$, the optimal temperature was assumed to be $20^{\circ} \mathrm{C}$.

\section{HT model}

The relationship between $\mathrm{GR}_{\mathrm{g}}$ and $\Psi$ was described by using the following equation:

$\theta_{\mathrm{H}}=\left[\Psi-\Psi_{\mathrm{b}}(\mathrm{g})\right] t_{\mathrm{g}}$

where $\theta_{\mathrm{H}}$ is the hydrotime (MPa d) constant of the seeds required for germination, $\Psi_{\mathrm{b}}(\mathrm{g})$ is the theoretical threshold or base $\Psi$ that will prevent the germination of fraction $\mathrm{g}$. The parameters in the HT model were estimated according to the equation:

$\operatorname{Probit}(\mathrm{g})=\left[\left(\Psi-\theta_{\mathrm{H}} / t_{\mathrm{g}}\right)-\Psi_{\mathrm{b}}(50)\right] / \sigma_{\psi \mathrm{b}}$

where $\Psi_{\mathrm{b}}(50)$ is the base water potential for attain the $50^{\text {th }}$ percentile of germination, and $\sigma_{{ }_{\mathrm{b}}}$ is the standard deviation of $\Psi_{\mathrm{b}}(\mathrm{g})$ in seed lots. To examine whether parameters of this model can be accurately used to quantify the sensitivity of seed populations to the variation of $\Psi$, the [1$(\Psi / \Psi(\mathrm{g}))] t_{\mathrm{g}}$ factor derived from Bradford (1990) was applied to normalize germination time courses at reduced $\Psi$ in this study. Germination time course can be normalized by this factor at any $\Psi$ to the corresponding time course that would occur in water for the seed population using the parameters from the HT model. All normalized data from different temperature conditions were plotted on a common thermal time scale, using the estimated $T_{\mathrm{b}}$ at $0 \mathrm{MPa}$.

\section{HTT model}

The HTT model describes seed germination patterns when $T$ and $\Psi$ both vary; Alvarado and 
Bradford, 2002). The relationship between $\mathrm{GR}_{\mathrm{g}}$ and variable conditions of $T$ and $\Psi$ are described by Eq. 3 for sub-optimal $T$, and modified Eq. 4 for supra-optimal $T$ :

$\theta_{\mathrm{HT}}=\left(T-T_{\mathrm{b}}\right)\left[\Psi-\Psi_{\mathrm{b}}(\mathrm{g})\right] t_{\mathrm{g}}$

$\theta_{\mathrm{HT}}=\left\{\Psi-\Psi_{\mathrm{b}}(\mathrm{g})-\left[K_{\mathrm{T}}\left(T-T_{\mathrm{o}}\right)\right]\right\}\left(T-T_{\mathrm{b}}\right) t_{\mathrm{g}}$

where $\theta_{\mathrm{HT}}$ is the hydrothermal constant and $T_{\mathrm{b}}$ is the base temperature. In Eq. $4,\left[K_{\mathrm{T}}\left(T-T_{\mathrm{o}}\right)\right]$ applies only in the supra-optimal range of $T$ and $K_{\mathrm{T}}$ is the slope of the relationship between $\Psi_{\mathrm{b}}(50)$ and temperatures when $T>T_{\mathrm{o}} ; T_{\mathrm{o}}$ is the optimum temperature. The value of $\Psi_{\mathrm{b}}(\mathrm{g})$ is set equal to the distribution of $\Psi_{\mathrm{b}}(\mathrm{g})$ at $T_{\mathrm{o}}$, and $\left(T-T_{\mathrm{b}}\right)$ is equal to $\left(T_{\mathrm{o}}-T_{\mathrm{b}}\right)$. Parameter values in above models can be obtained by probit analysis according to Eq. 5 and Eq. 6 for sub- and supraoptimal $T$, respectively.

$\operatorname{Probit}(\mathrm{g})=\left[\left(\Psi-\theta_{\mathrm{HT}} /\left(T-T_{\mathrm{b}}\right) t_{\mathrm{g}}\right)-\Psi_{\mathrm{b}}(50)\right] / \sigma_{\Psi \mathrm{b}}$

$\operatorname{Probit}(\mathrm{g})=\left[\left(\Psi-\theta_{\mathrm{HT}} /\left(T-T_{\mathrm{b}}\right) t_{\mathrm{g}}\right)-K_{\mathrm{T}}\left(T-T_{\mathrm{o}}\right)-\Psi_{\mathrm{b}}(50)\right] / \sigma_{\psi \mathrm{b}}$

As described in Alvarado and Bradford (2002), the values of $K_{\mathrm{T}}$ and $T_{\mathrm{o}}$ were varied for germination time courses at $T>T_{\mathrm{o}}$ until a fit was obtained that resulted in values of $\theta_{\mathrm{HT}}, \Psi_{\mathrm{b}}(50)$ and $\sigma_{\Psi \mathrm{b}}$ matching those obtained at or below $T_{\mathrm{o}}$.

\section{Statistical analyses}

A two-way analysis of variance (ANOVA) was carried out using SPSS 19.0 for Windows (SPSS Inc., Chicago, IL, USA) to evaluate the influence of $T, \Psi$, and their interactions on seed germination variables of $A$. teniussimum. The results showed with mean and SE value of four replicates. All probit analyses of HT and HTT models were fitted in SAS 8.2 statistical package (SAS Institute, Cary, NC, USA) using the PROC PROBIT routine, which employs a maximumlikelihood weighted regression method (Bradford, 1990; Dahal and Bradford, 1994).

\section{Results}

\section{Seed germination in response to temperature and water potential}

Results of analysis of variance indicated that the final germination percentage (FGP) of $A$. tenuissimum seeds was significantly influenced by $T(F=587.9, P<0.0001), \Psi(F=643.0, P<$ $0.0001)$, and their interactions $(F=24.2, P<0.0001)$ (Fig. 1, Table S1). When values of $\Psi$ remained constant, FGP increased as $T$ increased within sub-optimal ranges (11 to $20^{\circ} \mathrm{C}$ ), while it declined within supra-optimal ranges $\left(24\right.$ to $\left.28^{\circ} \mathrm{C}\right)$. In distilled water (i.e., $\left.\Psi=0 \mathrm{MPa}\right)$, FGP changed from $72.0 \pm 1.4$ to $94.8 \pm 1.4 \%$ over various $T$ conditions. Maximum FGP was observed at $20^{\circ} \mathrm{C}$ under all levels of $\Psi$ and ranged from $55.0 \pm 5.3$ to $94.8 \pm 1.4 \%$. For all $T$ settings, FGP decreased with decreasing $\Psi$ levels. Few seeds germinated under the combination of $-0.6 \mathrm{MPa}$ and $11^{\circ} \mathrm{C}$. In contrast, FGP reached $94.8 \pm 1.4 \%$ when seeds were incubated in water at $20^{\circ} \mathrm{C}$, indicating that the seeds in this analysis were non-dormant.

\section{Hydrotime analysis}

Parameters generated by the HT model are presented in Table 1. Values of $\theta_{\mathrm{H}}$ decreased from 6.4 $\mathrm{MPa} d$ at $11^{\circ} \mathrm{C}$ to $4.4,4.2,3.0$ and $3.0 \mathrm{MPa}$ d at $15,20,24$ and $28^{\circ} \mathrm{C}$, respectively. This suggests that the time required for germination declined as $T$ increased within sub-optimal 
ranges, while it remained constant at supra-optimal ranges. Values of $\Psi_{\mathrm{b}}(50)$ increased as $T$ increased from 11 to $28^{\circ} \mathrm{C}$. Notably, estimated values of $\Psi_{\mathrm{b}}(50)$ increased more positively at supra-optimal temperatures, rising from $-0.40 \mathrm{MPa}$ at $24^{\circ} \mathrm{C}$ to $-0.16 \mathrm{MPa}$ at $28{ }^{\circ} \mathrm{C}$. Values of $\sigma_{\varphi_{b}}$ varied from 0.20 to $0.37 \mathrm{MPa}$ across all regimes of $T$. Specifically, values of $\sigma_{\psi b}$ were nearly constant within the range of 15 to $24^{\circ} \mathrm{C}$, indicating that the variation in $\Psi_{\mathrm{b}}$ among all seeds in this $A$. tenuissimum population was small.

The curves in Fig. 2a-e are germination time courses predicted by HT model based on the $\Psi_{\mathrm{b}}(\mathrm{g})$ threshold distributions (Fig. 2F-G) and the estimated parameters (Table 1). At each $T$ setting, the predicted curves closely matched actual seed germination data under the various $\Psi$ levels (Fig. 2A-E). Normalization of germination time courses across various $\Psi$ levels at suband supra-optimal $T$ levels incorporated into a common curve are shown in Fig. 3. At suboptimal $T$, the difference between groupings of normalized observations and common curve is indistinct (Fig. 3A). However, the grouping of normalized observations at $28{ }^{\circ} \mathrm{C}$ did not resemble the profile from the common curve and fell into a distinct group (Fig. 3B). This indicates that the estimates of HT model interacted with $T$. Furthermore, these HT estimates consistently showed the largest shift in $\Psi_{\mathrm{b}}$ with increasing $T$ (Fig. 2F-G) and the grouping of normalized observations accurately predicted seed germination in this population.

\section{Hydrothermal time analysis}

Parameters for the HTT model, estimated in the sub- and supra-optimal $T$ ranges, are shown in Table 2. The hydrothermal time requirement $\left(\theta_{\mathrm{HT}}\right)$ for seed germination was $43.9 \mathrm{MPa}{ }^{\circ} \mathrm{C} \mathrm{d}$. Values $T_{\mathrm{b}}$ and $\Psi_{\mathrm{b}}(50)$ were estimated to be $7.0^{\circ} \mathrm{C}$ and $-0.67 \mathrm{MPa}$, respectively. FGP increased until $20.5{ }^{\circ} \mathrm{C}\left(T_{\mathrm{o}}\right)$, then it declined towards ceiling temperatures $\left(T_{\mathrm{c}}(\mathrm{g})\right)$, at which germination theoretically ceased when $T$ exceeded $T_{\mathrm{o}}$. In addition, $T_{\mathrm{c}}(50)$, the ceiling temperature for germination of $50 \%$, was $27.2{ }^{\circ} \mathrm{C}$. The estimates for $K_{\mathrm{T}}$ was $0.1 \mathrm{MPa}{ }^{\circ} \mathrm{C}^{-1}$, indicating that $\Psi$ declined by $0.1 \mathrm{MPa}$ for every degree that $T$ exceeds $T_{\mathrm{o}}$. Applying the HTT models using the $A$. tenuissimum germination data resulted in high $R^{2}$ values at both sub-optimal $\left(R^{2}=0.89\right)$ and supra-optimal $\left(R^{2}=0.81\right) T$ ranges, indicating a high degree of congruency between predicted and observed germination responses.

\section{Discussion}

\section{Seed germination of $A$. tenuissimum in response to various temperature and water availability conditions}

Successful establishment of cultivated plants depends on rapid and uniform seed germination (Fakhfakh et al., 2018; Bidgolya et al., 2018); however, suitable water availability and temperature conditions for seed germination are only available during a short period in most arid and semi-arid regions (Fakhfakh et al., 2018; Belo et al., 2014; Watt and Bloomberg, 2012). Here, we presented a comprehensive study of seed germination responses to different temperatures and water potential levels in A. tenuissimum, an important wild onion species from temperate-desert steppes of north central Asia (He, 2008; Li et al., 2011). Our results showed that final germination percentage of $A$. tenuissimum strongly depended on the interaction of these 
two factors. Furthermore, applying HTT models to our dataset provided insights into suitable conditions to enhance consistent germination responses of this valuable native species. Later, we discuss in detail the nuances of our results that underpin this methodological approach and expedite industrialization of wild species under stressful environmental conditions.

Numerous studies have illustrated how temperature-dependent seed germination is related to the geographical and ecological distribution of a particular species such as common vetch (Vicia sativa) (Liu, 2010), Stipa species (Ronnenberg et al., 2008) and temperate sedges (Carex) (Schütz and Rave, 1999). For A. tenuissimum, the final germination percentage was quite high (i.e., 92.5 to $94.8 \%$ ) in the temperature range of 15 to $20^{\circ} \mathrm{C}$ (Fig. 1). In some mediterranean grassland species, $15^{\circ} \mathrm{C}$ and $20^{\circ} \mathrm{C}$ also were found to be the best temperature for seed germination (Herranz et al., 1998; Marques and Draper, 2012). In contrast, the lower temperatures for preferable germination of A. tenuissimum seeds was consistent with a prior study of wild species of Allium distributed in temperate desert steppe (Zhao et al., 2011). In any constant temperatures, final germination percentage declined when seeds were incubated at reduced water potential levels (Fig. 1). This response is likely associated with enzyme activity and oxygen availability of seeds, which are known to decrease when germinated at unfavorable temperatures and limiting moisture conditions (Bewley and Black, 1994). Furthermore, higher incubation temperatures and more negative values of water potential during germination likely induced secondary dormancy of seeds, leading to prolonged seed germination over non-optimal temperatures and more negative water potential levels (Fig. 2).

\section{Predicting seed germination with mathematical models}

Mathematical models to predict and quantify the influence of environmental factors on seed germination are essential when little information is known about the ideal conditions for potential agronomic species such as zucchini (Cucurbita pepo) (Atashi et al., 2015), red brome (Bromus rubens) and cheatgrass (Bromus tectorum) (Horn et al., 2015), and safflowers (Carthamus tinctorius)( Bidgolya et al., 2018). While accounting for the influence of only temperature, TT models can successfully predict germination time courses in sub-optimal temperature ranges, but they become less effective at predicting germination in supra-optimal temperature ranges (Bradford, 2002; Bewley et al., 2013), which spurred the development of hydrothermal models combine the influences of temperature and water availability on seed germination (Windauer et al., 2012). Such HT and HTT models have been widely applied and accurately describe seed germination across variable temperatures and water potential levels (Alvarado and Bradford, 2002; Bakhshandeh et al., 2015, 2017). In addition, normalizing thermal time scales, as we did for the germination time courses of A. tenuissimum (Bradford, 1990, 2002), accurately described the influences of temperature and water availability (Fig. 3A). However, the grouping of normalized observations at $28^{\circ} \mathrm{C}$ fell into a distinct group instead of resembling the profile from the common curve (Fig. 3B). Similarly, previous studies documented that HT analysis was unable to predict the germination time courses at supra-optimal temperatures (Bakhshandeh et al., 2017; Rowse and Finch-Savage, 2010), suggesting that HT estimates were not consistent across variable temperatures. In other words, grouping of 
254

255

256

257

258

259

260

261

262

263

264

265

266

267

268

269

270

271

272

273

274

275

276

277

278

279

280

281

282

283

284

285

286

287

288

289

290

291

292

293

normalized observations resulted in large shifts in the theoretical threshold or base water potential $\left(\Psi_{\mathrm{b}}(\mathrm{g})\right)$ that can prevent the fraction of germination as temperature increases (Rong et al., 2015). Furthermore, when the distribution of $\Psi_{\mathrm{b}}(\mathrm{g})$ overlaps with $0 \mathrm{MPa}$ at a given temperature, germination of some seeds may be inhibited (Alvarado and Bradford, 2002; Larsen et al., 2004; Watt et al., 2011). For this reason, Alvarado and Bradford (2002) developed the HTT model to account for the linear increase of $\Psi_{\mathrm{b}}(\mathrm{g})$ value as temperature increased above $T_{\mathrm{o}}$ in order to eliminate the positive shift in $\Psi_{\mathrm{b}}(\mathrm{g})$ values at supra-optimal temperatures. This modified model can quantify and predict both final germination percentage and germination rate across different temperatures and water potential levels at which seed germination occurs (Bakhshandeh et al., 2015; Rowse and Finch-Savage, 2010) as we observed for germination time course of $A$. tenuissimum seeds at supra-optimal temperatures, which were well described by HTT model (i.e., $\left.R^{2}=0.81\right)$.

\section{Model parameters and their biological roles}

Because changes in dormancy state are related to $\Psi_{\mathrm{b}}$ (Meyer et al., 2000) and high temperatures often induce secondary dormancy, soil water availability is critical for seed germination at supraoptimal temperatures (Hills et al., 2003). Likewise, values of $\Psi_{\mathrm{b}}(50)(-0.74$ to $-0.16 \mathrm{MPa})$ determined in our analysis revealed that seeds of $A$. tenuissimum are relatively sensitive to water restrictions at temperatures above $T_{\mathrm{o}}$. Thus, seeds of $A$. tenuissimum should be germinated at sub-optimal temperatures to enhance crop establishment in arid and semi-arid regions. Results from HT analysis also indicated that the minimum value of $\Psi_{\mathrm{b}}(50)$ was observed at $11^{\circ} \mathrm{C}$ and then increased, particularly in supra-optimal temperature ranges. Similar to our results, the linear increase of $\Psi_{\mathrm{b}}(50)$ has been observed in zucchini (Atashi et al., 2015), watermelon (Bakhshandeh et al., 2015), and sesame (Bakhshandeh et al., 2017). In general, the $\Psi_{\mathrm{b}}(50)$ value of a seed lot gives an indication of its tolerance to water stress. If water potential levels are more negative than $\Psi_{\mathrm{b}}(50)$, germination times will be extended and germination rates will be reduced (Bradford, 2002). This could be caused by a decrease in both enzyme activity and oxygen availability during the seed germination period, particularly when germinated at supra-optimal temperatures (Bewley et al., 2013). When soil temperature approaches $T_{\mathrm{o}}$, less negative water potential levels will cause an increase in the activity of enzymes and water uptake rate (Kebreab and Murdoch, 1999).

Base water potential coefficient $\left(\sigma_{{ }_{\mathrm{b}}}\right)$ is related to life history strategy of various species (Bradford, 1990) and indicates the uniformity of seed germination among individual seeds within a seed lot. A smaller value of $\sigma_{\psi \mathrm{b}}$ represents an increasingly uniform germination among seed population (Bradford and Still, 2004; Bidgolya et al., 2018). The values of $\sigma_{\Psi \mathrm{b}}$ we estimated for A. tenuissimum seeds varied from 0.20 to $0.37 \mathrm{MPa}$, indicating that there was less variation in $\Psi_{\mathrm{b}}$ among individual seeds and that uniform germination was observed. This pattern is likely a reflection of survival adaptations to harsh environments. Under initial favorable soil temperature and water availability, faster and uniform germination will allow plants to possibly dominate a plant community in space and time (Wang et al., 2009). In contrast, most plant populations must adopt a different germination strategy to mitigate the harsh environment-induced damage on 
294

295

296

297

298

299

germination by allowing a few seeds to rapidly germinate, and then delaying germination until consistent suitable environment conditions are reached before the remaining seeds germinate (Bradford, 1990; Batlla et al., 2009; Watt et al., 2011; Rong et al., 2015). Consistent with our results, the variation of $\Psi_{\mathrm{b}}$ was small and $\sigma_{\psi \mathrm{b}}$ varied from 0.16 to $0.31 \mathrm{MPa}$ among Vicia sativa seeds ( $L i u, 2010)$, indicating that the long-term cultivation and domestication can result in uniform germination.

The hydrotime (MPa d) constant of the seeds required for germination $\left(\theta_{\mathrm{H}}\right)$ represents the inherent speed of seed germination in a seed lot (Bradford and Still, 2004). Our results showed that $\theta_{\mathrm{H}}$ declined from 6.4 to $3.0 \mathrm{MPa}$ as temperature increased from $11{ }^{\circ} \mathrm{C}$ to $24^{\circ} \mathrm{C}$, indicating that germination rate was faster at higher temperatures (Fig. 2, Table 1). Similarly, other studies reported that $\theta_{\mathrm{H}}$ was constant in supra-optimal temperature ranges, but it increased as temperature declined in the range of sub-optimal temperatures (Bakhshandeh et al., 2015; Dahal and Bradford, 1994). Thus, seed germination was greatly altered with decreasing temperature.

Seed germination responses to temperature are commonly characterized with three cardinal temperatures $\left(T_{\mathrm{b}}, T_{\mathrm{o}}\right.$ and $\left.T_{\mathrm{c}}\right)$ estimated according to the HTT model (Bewley et al., 2013). These cardinal temperatures of $A$. tenuissimum seeds were $T_{\mathrm{b}}=7.0^{\circ} \mathrm{C}, T_{\mathrm{o}}=20.5^{\circ} \mathrm{C}$, and $T_{\mathrm{c}}(50)=27.2$ ${ }^{\circ} \mathrm{C}$, respectively. In practical terms, these values suggest $A$. tenuissimum seeds should not be sown in soils where temperature do not exceed $7.0^{\circ} \mathrm{C}$. Maximum final germination percentage would be observed as soil temperature approaches $20.5^{\circ} \mathrm{C}$, a value when some seeds within the population will probably germinate quickly if they are not exposed to water stress or dormancy induction within optimal ranges (Rong et al., 2015; Windauer et al., 2012). In addition, because seeds of $A$. tenuissimum germinated in a relatively narrow range of temperature according to estimations of $T_{\mathrm{c}}(50)$, seeds of $A$. tenuissimum are likely unable to tolerate high soil temperature. From a crop production standpoint, our results document that seed germination of $A$. tenuissimum occurs over a soil temperature range of 7.0 to $27.2^{\circ} \mathrm{C}$, but $20.5^{\circ} \mathrm{C}$ is the optimal temperature. These estimated cardinal temperatures are consistent with wild Allium species (Zhao et al., 2011).

\section{Conclusions}

The mathematical models or the estimated value of parameters can be used to quantitatively predict the seed germination of $A$. tenuissimum under various $\mathrm{T}$ and $\Psi$ conditions. Soil temperature for seed germination of A. tenuissimum should be at the range of $7.0^{\circ} \mathrm{C}$ to $27.2^{\circ} \mathrm{C}$, and the optimum temperature is $20.5^{\circ} \mathrm{C}$. The water potential should be less negative than -0.67 MPa. The relatively lower $\mathrm{T}_{\mathrm{b}}$ and more negative $\Psi_{\mathrm{b}}(50)$ indicate that this wild Allium species might be established in arid and semi-arid regions, while relatively narrow threshold in response to $\mathrm{T}$ and $\Psi$ variations might sufficiently delay or even prevent seed germination in extreme arid or harsh desert regions.

\section{Acknowledgments}

This research was supported by the National Key Research and Development Program of China (2016YFC0500603), the National Natural Science Foundation of China (31772653) and National 
Natural Science Foundation of China (31472136).

\section{References}

Abdellaoui R, Boughalleb F, Zayoud D, Neffati M, Bakhshandeh E (2019) Quantification of Retama raetam seed germination response to temperature and water potential using hydrothermal time concept. Environ Exp Bot 157:211-216 DOI 10.1016/j.envexpbot.2018.10.014.

Alvarado V, Bradford KJ (2002) A hydrothermal time model explains the cardinal temperatures for seed germination. Plant Cell Environ 25:1061-1069 DOI 10.1046/j.13653040.2002.00894.x.

Atashi S, Bakhshandeh E, Mehdipour M, Jamali M, Teixeira Da Silva JA (2015) Application of a hydrothermal time seed germination model using the Weibull distribution to describe base water potential in zucchini (Cucurbita pepo L.). J Plant Growth Regul 34:150-157 DOI 10.1007/s00344-014-9452-y.

Bakhshandeh E, Atashi S, Hafeznia M, Pirdashti H (2013) Quantification of the response of germination rate to temperature in sesame (Sesamum indicum). Seed Sci Technol 41:469-473 DOI 10.15258/sst.2013.41.3.14.

Bakhshandeh E, Atashi S, Hafeznia M, Pirdashti H, Teixeira Da Silva JA (2015) Hydrothermal time analysis of watermelon (Citrullus vulgaris cv. 'Crimson sweet') seed germination. Acta Physiol Plant 37:1738 DOI 10.1007/s11738-014-1738-y.

Bakhshandeh E, Gholamhossieni M (2018) Quantification of soybean seed germination response to seed deterioration under PEG-induced water stress using hydrotime concept. Acta Physiol Plant 40:126 DOI 10.1007/s11738-018-2700-1

Bakhshandeh E, Gholamhossieni M (2019) Modelling the Effects of Water Stress and Temperature on Seed Germination of Radish and Cantaloupe. J Plant Growth Regul 38:14021411 DOI 10.1007/s00344-019-09942-9

Bakhshandeh E, Jamali M, Afshoon E, Gholamhossieni M (2017) Using hydrothermal time concept to describe sesame (Sesamum indicum L.) seed germination response to temperature and water potential. Acta Physiol Plant 39:250 DOI 10.1007/s11738-017-2549-8.

Batlla D, Grundy A, Dent KC, Clay HA, Finch-Savage WE (2009) A quantitative analysis of temperature-dependent dormancy changes in Polygonum aviculare seeds. Weed Res 49:428438 DOI 10.1111/j.1365-3180.2009.00706.x.

Belo RG, Tognetti J, Benech-Arnold R, Izquierdo NG (2014) Germination responses to temperature and water potential as affected by seed oil composition in sunflower. Ind Crop Prod 62:537-544 DOI 10.1016/j.indcrop.2014.09.029.

Bewley JD, Black M (1994) Seeds: physiology of development and germination. New York:Plenum Press

Bewley JD, Bradford K, Hilhorst H, Nonogaki H (2013) Seeds: physiology of development, germination and dormancy. 3rd edn. Springer, New York, pp 407

Bidgolya RO, Balouchi H, Soltani E, Moradi A (2018) Effect of temperature and water potential on Carthamus tinctorius L. seed germination: Quantification of the cardinal temperatures and 
modeling using hydrothermal time. Ind Crop Prod 113:121-127 DOI 10.1016/j.indcrop.2018.01.017.

Bradford KJ (1990) A water relations analysis of seed germination rates. Plant Physiol 94:840849 DOI 10.1104/pp.94.2.840.

Bradford KJ (2002) Applications of hydrothermal time to quantifying and modeling seed germination and dormancy. Weed Sci 50:248-260 DOI 10.1614/0043-1745.

Bradford KJ, Still DW (2004) Applications of hydrotime analysis in seed testing. Seed Technol 26:75-85 https://www.jstor.org/stable/23433495.

Dahal P, Bradford KJ (1990) Effects of priming and endosperm integrity on seed-germination rates of tomato genotypes. 2. Germination at reduced water potential. J Exp Bot 41:14411453 DOI 10.1093/jxb/41.11.1441.

Dahal P, Bradford KJ (1994) Hydrothermal time analysis of tomato seed germination at suboptimal temperature and reduced water potential. Seed Sci Res 4:71-80 DOI 10.1017/S096025850000204X.

Fakhfakh LM, Anjum NA, Chaieb M (2018) Effects of temperature and water limitation on the germination of Stipagrostis ciliata seeds collected from Sidi Bouzid Governorate in Central Tunisia. J Arid Land 10:304-315 DOI 10.1007/s40333-018-0050-x.

Fischer RA, Turner NC (1978) Plant productivity in the arid and semiarid zones. Annu Rev Plant Physiol 29:277-317 DOI 10.1146/annurev.pp.29.060178.001425.

Gummerson RJ (1986) The effect of constant temperatures and osmotic potentials on the germination of sugar beet. J Exp Bot 37:729-741 DOI 10.1093/jxb/37.6.729.

He XL (2008) Study on biology characteristics and exploitation and utilization of Allium tenuissimum L. J Anhui Agr Sci 36:1814 [In Chinese]

Herranz JM, Ferrandis P, Martínez-Sánchez JJ (1998) Influence of heat on seed germination of seven mediterranean leguminosae species. Plant Ecol 136(1):95-103 DOI 10.1023/A:1009702318641.

Hills PN, Staden JV, Thomas TH (2003) Thermoinhibition of seed germination. S Afr J Bot 69:455-461 DOI 10.1016/S0254-6299(15)30281-7.

Horn KJ, Nettles R, Clair SBS (2015) Germination response to temperature and moisture to predict distributions of the invasive grass red brome and wildfire. Biol Invasions 17:18491857 DOI 10.1007/s10530-015-0841-3.

Izquierdo J, Bastida F, Lezaún JM, Sánchez Del Arco MJ, Gonzalez-Andujar JL (2013) Development and evaluation of a model for predicting Lolium rigidum emergence in winter cereal crops in the Mediterranean area. Weed Res 53:269-278 DOI 10.1111/wre.12023.

Juan-Vicedo J, Fernández-Pereira J, Ríos S, Casas, JL, Martín I (2016) Seed germination and storage behaviour of lapiedra martinezii (amaryllidaceae). Seed Sci and Technol 44(1):199206 DOI 10.15258/sst.2016.44.1.02

Kebreab E, Murdoch AJ (1999) Modelling the effects of water stress and temperature on germination rate of Orobanche aegyptiaca seeds. J Exp Bot 50:655-664 DOI $10.1093 / \mathrm{jxb} / 50.334 .655$. 
Larsen SU, Bailly C, Come D, Corbineau F (2004) Use of the hydrothermal time model to analyse interacting effects of water and temperature on germination of three grass species. Seed Sci Res 14:35-50 DOI 10.1079/SSR2003153.

Li LY, Zhang WF (2011) Study on the condiment industrialization of Allium tenuissimum L. Heilongjiang Agr Sci (9):104-106 [In Chinese].

Li LY, Zhang WF, Zhang SZ, Zheng LS, Fan LS (2011) Study on biology characteristics of developmental rhythm of annual plants of Allium tenuissimum L. Heilongiiang Agr Sci (5):68-70 [In Chinese]

Li LY, Zhang WF, Zheng LS, Guo YD, Li QZ (2013) Artificial cultivation techniques of Allium tenuissimum L. Heilongjiang Agr Sci (12):161-162 [In Chinese].

Liu GX, Wang BB, Lin YJ, Liang X, An Y, Liu ZK (2016) Analysis of agronomic characters of four Allium species under wild and cultivated conditions. North Hortic (4):1-5 [In Chinese].

Liu SS (2010) A study on germination threshold models of common vetch (Vicia sativa L.) seeds. Dissertation, China Agricultural University [In Chinese].

Marques I, Draper D (2012) Seed germination and longevity of autumn-flowering and autumnseed producing Mediterranean geophytes. Seed Sci Res 22(4):299-309 DOI 10.1017/S0960258512000153

Mccartan SA, Jinks RL, Barsoum N (2015) Using thermal time models to predict the impact of assisted migration on the synchronization of germination and shoot emergence of oak (quercus robur L.). Ann of Forest Sci 72(4):479-487 DOI 10.1007/s13595-014-0454-5

Meyer SE, Debaenegill SB, Allen PS (2000) Using hydrothermal time concepts to model seed germination response to temperature, dormancy loss, and priming effects in Elymus elymoides. Seed Sci Res 10:213-223 DOI 10.1017/S0960258500000246.

Rawlins JK, Roundy BA, Davis SM, Egget D (2012) Predicting germination in semi-arid wildland seedbeds. I. Thermal germination models. Environ Exp Bot 76:60-67 DOI 10.1016/j.envexpbot.2011.10.003.

Rong Y, Li H, Johnson DA (2015) Germination response of Apocynum venetum seeds to temperature and water potential. J Appl Bot Food Qual 88:202-208 DOI 10.5073/JABFQ.2015.088.029.

Ronnenberg K, Wesche K, Hensen I (2008) Germination ecology of Central Asian Stipa spp: differences among species, seed provenances, and the importance of field studies. Plant Ecol 196:269-280 DOI 10.1007/s11258-007-9351-4.

Rowse HR, Finch-Savage WE (2010) Hydrothermal threshold models can describe the germination response of carrot (Daucus carota) and onion (Allium cepa) seed populations across both sub- and supra-optimal temperatures. New Phytol 158:101-108 DOI 10.1046/j.1469-8137.2003.00707.x.

Saleem MH, Ali S, Seleiman MF, Rizwan M, Rehman M, Aisha Akram N, Liu L, Alotaibi M, Al-Ashkar I, Mubushar M (2019) Assessing the Correlations between Different Traits in Copper-Sensitive and Copper-Resistant Varieties of Jute (Corchorus capsularis L.). Plants 8: 545 DOI 10.3390/plants8120545 
Schütz W, Rave G (1999) The effect of cold stratification and light on the seed germination of temperate sedges (Carex) from various habitats and implications for regenerative strategies. Plant Ecol 144:215-230 DOI 10.1023/A:1009892004730.

Soltani E, Adeli R, Akbari GA, Ramshini H (2017) Application of hydrotime model to predict early vigour of rapeseed (Brassica napus L.) under abiotic stresses. Acta Physiol Plant 39:252 DOI 10.1007/s11738-017-2552-0.

Song B, Niu S, Wan S (2016) Precipitation regulates plant gas exchange and its long-term response to climate change in a temperate grassland. J Plant Ecol 9:531-541 DOI 10.1093/jpe/rtw010.

Tobe K, Zhang L, Qiu GY, Shimizu H, Omasa K (2001) Characteristics of seed germination in five non-halophytic Chinese desert shrub species. J Arid Environ 47:191-201 DOI 10.1006/jare.2000.0689.

Torabi B, Soltani E, Archontoulis SV, Rabii A (2016) Temperature and water potential effects on Carthamus tinctorius L. seed germination: measurements and modeling using hydrothermal and multiplicative approaches. Braz J Bot 39:427-436 DOI 10.1007/s40415015-0243-x.

Trudgill DL, Honek A, Li D, Van Straalen, NM (2005) Thermal time-concepts and utility. Ann Appl Biol 146:1-14 DOI 10.1111/j.1744-7348.2005.04088.x.

Wang JH, Du GZ, Cui XL, Zheng XF, Qi W (2009) Germination characteristics of 61 common woody species from the eastern Qinghai-Tibet Plateau of China and their life history correlates. Chinese J Plant Ecol 33:171-179 [In Chinese].

Watt MS, Bloomberg M, Finch-Savage WE (2011) Development of a hydrothermal time model that accurately characterises how thermoinhibition regulates seed germination. Plant Cell Environ 34:870-876 DOI 10.1111/j.1365-3040.2011.02292.x.

Watt MS and Bloomberg M (2012) Key features of the seed germination response to high temperatures. New Phytol, 196:332-336 DOI 10.1111/j.1469-8137.2012.04280.x.

Windauer LB, Martinez J, Rapoport D, Wassner D, Benech-Arnold R (2012) Germination responses to temperature and water potential in Jatropha curcas seeds: a hydrotime model explains the difference between dormancy expression and dormancy induction at different incubation temperatures. Ann Bot 109:265-273 DOI 10.1093/aob/mcr242.

Xu MJ, Zhang J, Li MP, Yu LG, Guo CX, Zhang SW (2017) Analysis of the volatile compounds in the flowers of Allium tenuissimum by headspace-gas chromatography-olfactometry-mass spectrometry. Food Sci 38:199-203 [In Chinese].

Zhang WF, Li LY, Zheng LS (2014) Harvesting and preservation techniques of Allium tenuissimum L. Modern Agr Sci Technol (17):124-125 [In Chinese].

Zhang XL, Liu LM (2012) Study on extraction process of flower essential oil in Allium tenuissimum L. by supercritical $\mathrm{CO}_{2}$ fluid. China Condiment 37:74-78 [In Chinese].

Zhao JH (2010) A study on ecological adaptability and reproduction feature of three wild Allium plants. Dissertation, Inner Mongolia Agricultural University [In Chinese].

Zhao JH, Li QF, Badema GLB (2011) Studies on seed imbibition characteristics of three wild 
493 Allium plants in Inner Mongolia. Seed 30:95-98 [In Chinese]. 


\section{Table $\mathbf{1}$ (on next page)}

Parameters of the hydrotime model characterizing germination of $A$. tenuissimum seeds across a range of temperatures.

The hydrotime time model (Eq. 2) was fitted to data from four water potential levels (0, -0.2 , -0.4 and $-0.6 \mathrm{MPa})$ at five temperature regimes $\left(11,15,20,24\right.$ and $\left.28^{\circ} \mathrm{C}\right) . \theta_{\mathrm{H}}$, hydrotime constant; $\psi_{\mathrm{b}}(50)$, base water potential for $50 \%$ seed germination; $\sigma_{\psi_{b}}$, standard deviation for $\psi_{\mathrm{b}}(\mathrm{g}) ; R^{2}$, coefficient of determination 


\begin{tabular}{lllll}
\hline $\begin{array}{l}\text { Temperature } \\
\left({ }^{\circ} \mathrm{C}\right)\end{array}$ & $\begin{array}{l}\theta_{\mathrm{H}} \\
(\mathrm{MPa} \mathrm{d})\end{array}$ & $\begin{array}{l}\Psi_{\mathrm{b}}(50) \\
(\mathrm{MPa})\end{array}$ & $\begin{array}{l}\sigma_{\Psi \mathrm{b}} \\
(\mathrm{MPa})\end{array}$ & $R^{2}$ \\
\hline 11 & 6.4 & -0.74 & 0.20 & 0.95 \\
15 & 4.4 & -0.60 & 0.29 & 0.97 \\
20 & 4.2 & -0.49 & 0.27 & 0.92 \\
24 & 3.0 & -0.40 & 0.28 & 0.90 \\
28 & 3.0 & -0.16 & 0.37 & 0.94 \\
\hline
\end{tabular}

1 


\section{Table 2 (on next page)}

Parameters of the hydrothermal time model characterizing germination of $A$. tenuissimum seeds at sub-optimal and supra-optimal $T$.

$T_{b}$, base temperature; $T_{0}$, optimal temperature; $\theta_{H T}$, hydrothermal time constant; $\psi_{b}(50)$, base water potential for $50 \%$ seed germination; $\sigma_{\psi b}$, standard deviation for $\psi_{b}(\mathrm{~g}) ; R^{2}$, coefficient of determination; $K_{\mathrm{T}}$, the slope of the relationship between $\psi_{\mathrm{b}}(50)$ and temperatures when $T$ exceeds $T_{0} \cdot T_{\mathrm{c}}(50)$, ceiling temperature to germination of $50 \%$. The value of $T_{\mathrm{c}}(50)$ was calculated by parameters found after fitting the HTT model at supra-optimal $T$ (Eq. 6). 


\begin{tabular}{lll}
\hline $\begin{array}{l}\text { hydrothermal time model } \\
\text { Parameters }\end{array}$ & sub-optimal $T$ & supra-optimal $T$ \\
\hline$T_{\mathrm{b}}\left({ }^{\circ} \mathrm{C}\right)$ & 7.0 & 7.0 \\
$\theta_{\mathrm{HT}}\left(\mathrm{MPa}{ }^{\circ} \mathrm{C} \mathrm{d}\right)$ & 43.9 & 43.9 \\
$\Psi_{\mathrm{b}}(50)(\mathrm{MPa})$ & -0.67 & -0.67 \\
$\sigma_{\Psi \mathrm{b}}(\mathrm{MPa})$ & 0.28 & 0.32 \\
$R^{2}$ & 0.89 & 0.81 \\
$T_{\mathrm{o}}\left({ }^{\circ} \mathrm{C}\right)$ & - & 20.5 \\
$T_{\mathrm{c}}(50)\left({ }^{\circ} \mathrm{C}\right)$ & - & 27.2 \\
$K_{\mathrm{T}}\left(\mathrm{MPa}{ }^{\circ} \mathrm{C}^{-1}\right)$ & - & 0.1 \\
\hline
\end{tabular}

1 
Figure 1

Mean ( \pm standard error) final germination percentage of $A$. tenuissimum seeds under variable temperature $\left(T=11,15,20,24\right.$, and $\left.28^{\circ} \mathrm{C}\right)$ and water potential $(\Psi=0,-0.2$, -0.4 , and -0.6 MPa) levels

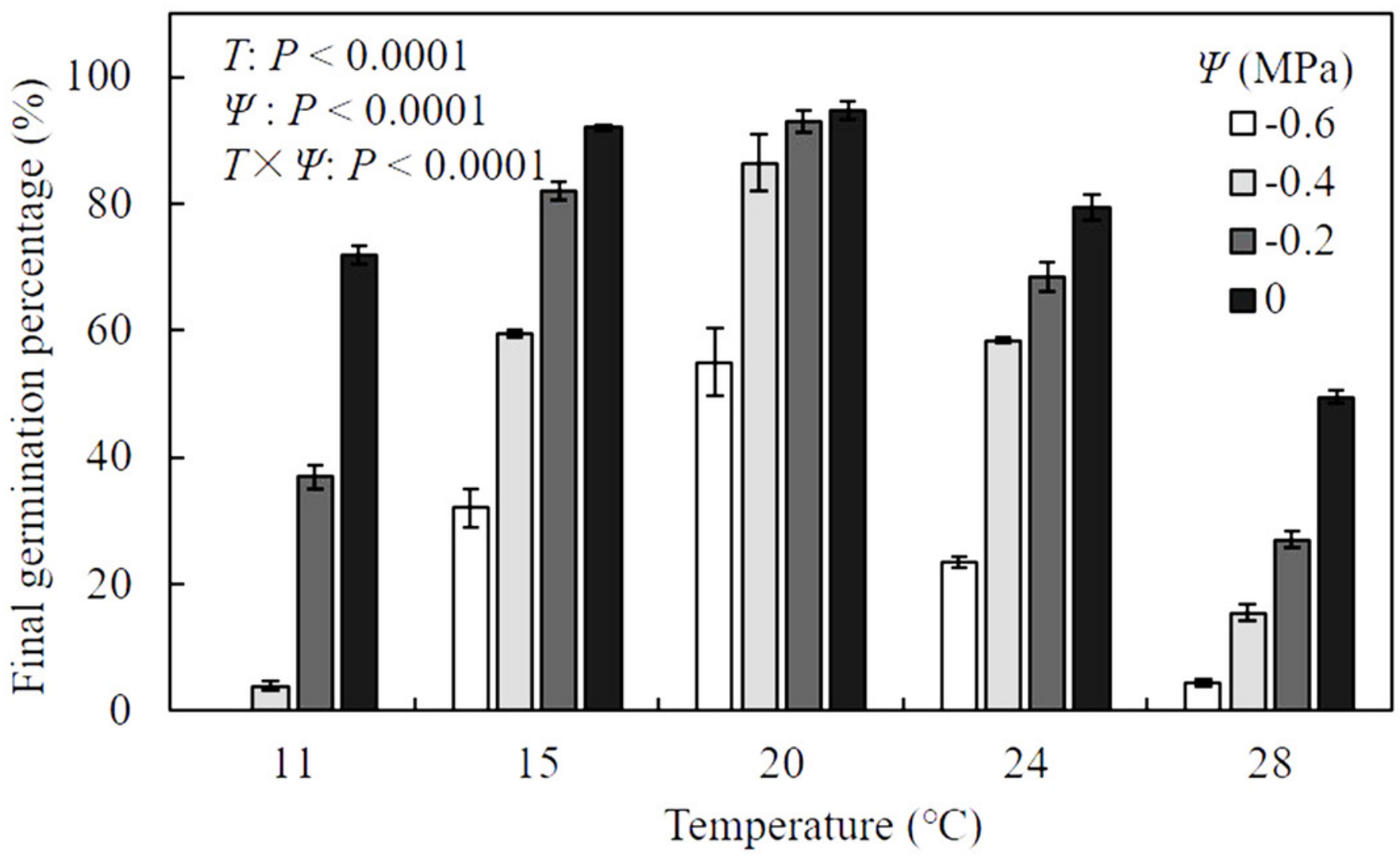




\section{Figure 2}

Germination time courses of $A$. tenuissimum seeds across a range of water potential and temperature $(A-E)$ and normal distributions of the relative frequencies of base water potential at each temperature $\left(11,15,20,24\right.$ and $\left.28^{\circ} \mathrm{C}\right)(\mathrm{F}-\mathrm{G})$.

Symbols represent actual data and lines indicate values predicted by probit analysis using the parameters presented in Table 1 


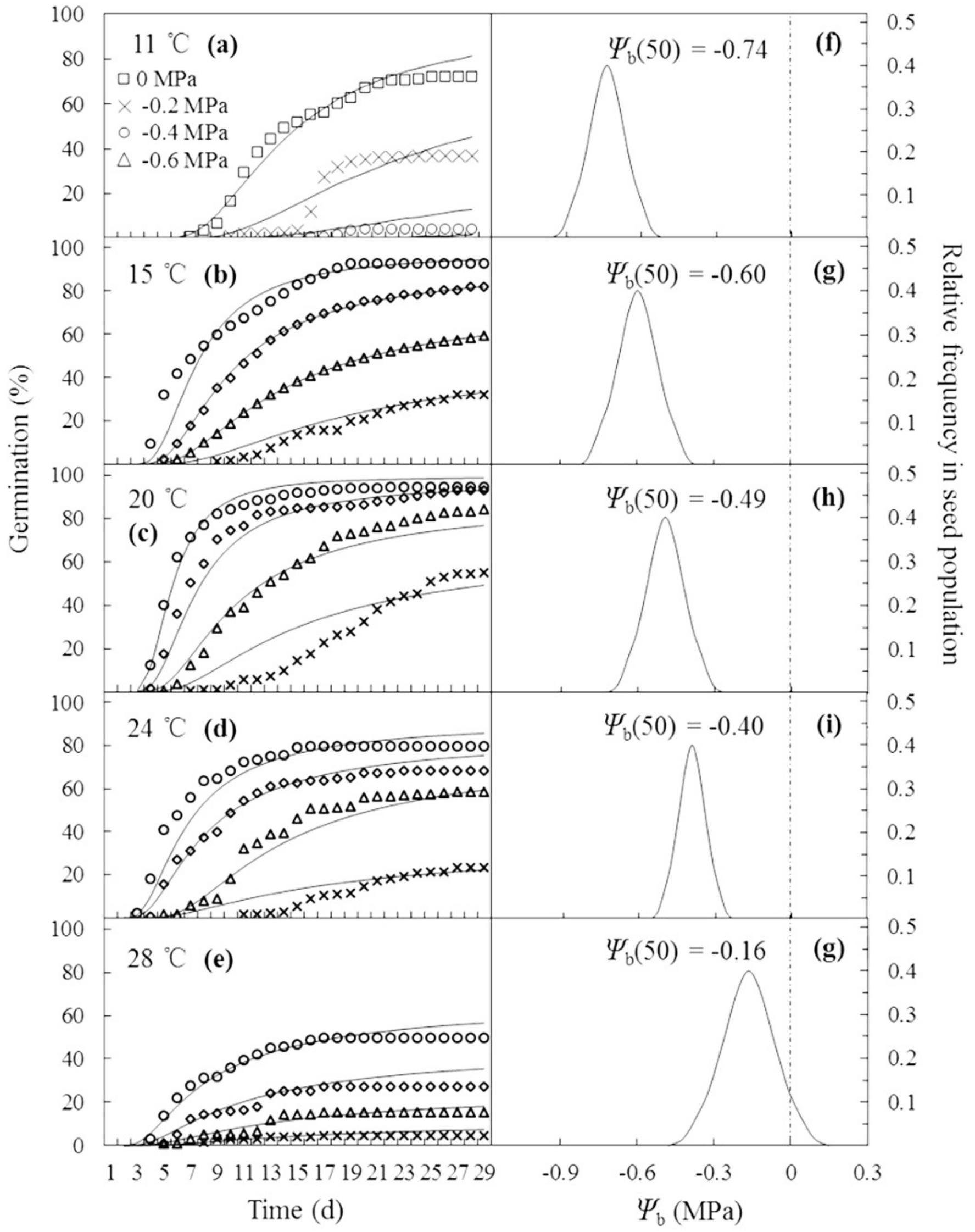


Figure 3

Normalized time courses of the sub- and supra-optimal hydrotime models.

(A) Germination data from Fig. $2 \mathrm{~A}-\mathrm{C}$ is plotted on a normalized thermal time scale showing the predicted time courses in water according to the parameters of sub-optimal $T$ shown in Table 2. (B) Germination data from Fig. 2D-E are plotted on a normalized time scale showing the predicted time courses in water according to the parameters of supra-optimal $T$ shown in Table 2. (C) Germination time courses across all $T$ and $\psi$ shown in Fig. 2A-E merged into a single normalized thermal time scale

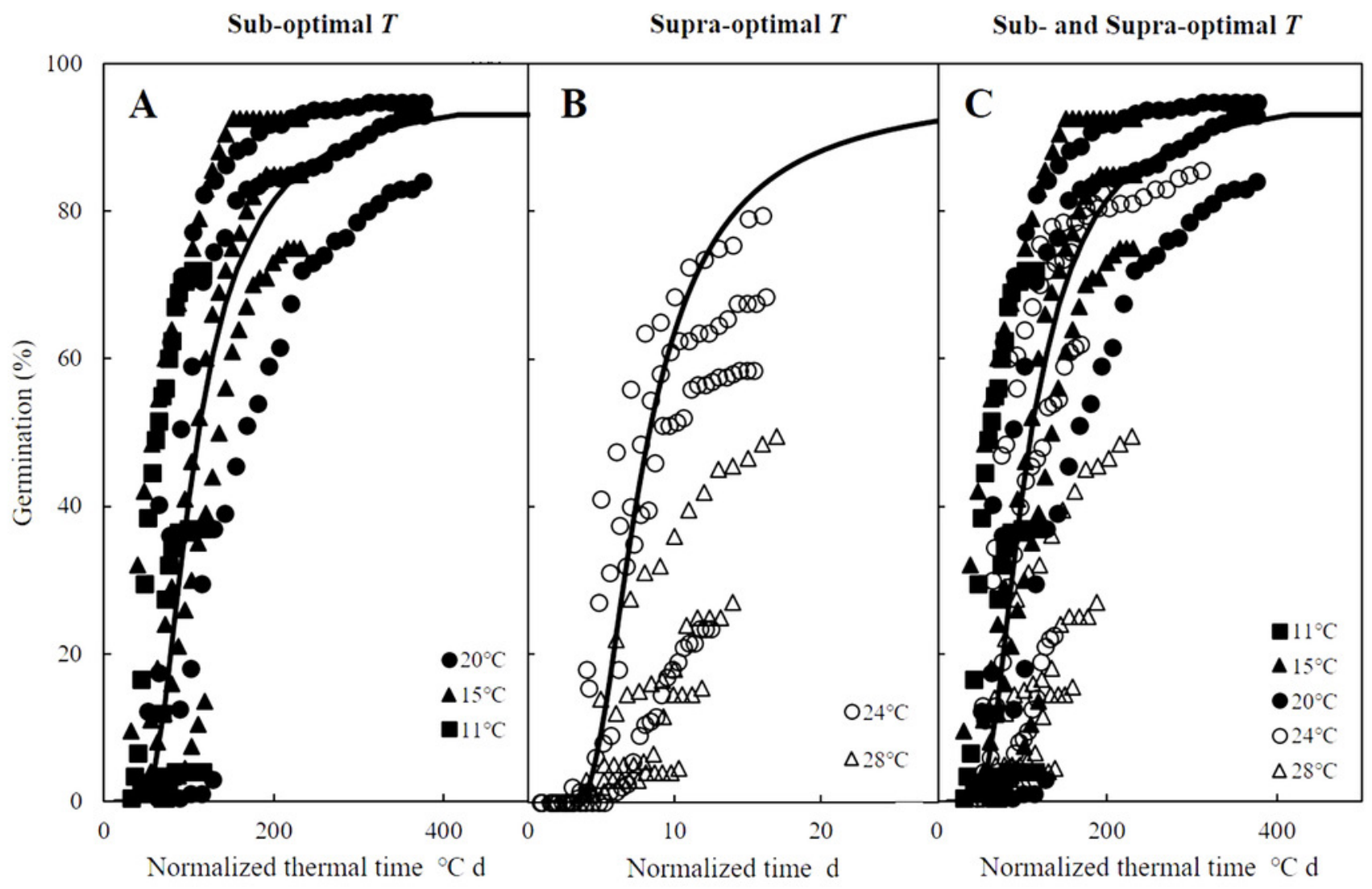

